\title{
Hydroformylation of Cyclohexene with Carbon Dioxide and Hydrogen Using Ruthenium Carbonyl Catalyst: Influence of Pressures of Gaseous Components
}

\author{
Shin-ichiro Fujita, Shuhei Okamura, Yoshinari Akiyama and Masahiko Arai * \\ Division of Chemical Process Engineering, Graduate School of Engineering, Hokkaido University, \\ Sapporo 060-8628, Japan
}

* Author to whom correspondence should be addressed; E-mail: marai@eng.hokudai.ac.jp

Received: 29 May 2007; in Revised Form: 11 July 2007 / Accepted:23 July 2007 /

Published: 2 August 2007

\begin{abstract}
Hydroformylation of cyclohexene was studied with a catalyst system of $\mathrm{Ru}_{3}(\mathrm{CO})_{12}$ and $\mathrm{LiCl}$ using $\mathrm{H}_{2}$ and $\mathrm{CO}_{2}$ instead of $\mathrm{CO}$ in NMP. The influence of $\mathrm{H}_{2}$ and $\mathrm{CO}_{2}$ pressures on the total conversion and the product distribution was examined. It was shown that increasing total pressure of $\mathrm{H}_{2}$ and $\mathrm{CO}_{2}$ promoted the reverse water gas shift reaction and increased the yield of cyclohexanecarboxaldehyde. Its hydrogenation to cyclohexanemethanol was promoted with increasing $\mathrm{H}_{2}$ pressure but suppressed with increasing $\mathrm{CO}_{2}$ pressure. Cyclohexane was also formed along with those products and this direct hydrogenation was suppressed with increasing $\mathrm{CO}_{2}$ pressure. The roles of $\mathrm{CO}_{2}$ as a promoter as well as a reactant were further examined by phase behavior observations and high pressure FTIR measurements.
\end{abstract}

Keywords: hydroformylation, ruthenium carbonyl catalyst, lithium chloride promoter, carbon dioxide, pressure effect

\section{Introduction}

Carbon dioxide $\left(\mathrm{CO}_{2}\right)$ has been attracting increasing attention from green chemistry concept because of its safety, cost, and wide utility as a reaction medium at high pressures [1-4] and as a reactant for several organic synthetic reactions [5-7]. When suitable catalysts and reaction conditions are chosen, $\mathrm{CO}_{2}$ may replace conventional harmful organic solvents and reactants such as carbon 
monoxide, phosgene, and so on. Hydroformylation is one of practically important chemical processes for the production of aldehydes and alcohols from olefins and syngas $\left(\mathrm{CO}, \mathrm{H}_{2}\right)$ [8,9]. Many authors investigated hydroformylation reactions in dense $\mathrm{CO}_{2}$ using homogeneous and heterogeneous catalysts and reported the positive features of such a high pressure $\mathrm{CO}_{2}$ solvent [10]. However, few attempts were made so far to use $\mathrm{CO}_{2}$ as a reactant instead of $\mathrm{CO}$ in hydroformylation reactions. Recently Tominaga and Sasaki have first shown that the hydroformylation can indeed proceed with a mixture of $\mathrm{CO}_{2}$ and $\mathrm{H}_{2}$ [11,12]. After screening several catalysts, they found an active catalyst system of $\mathrm{Ru}_{3}(\mathrm{CO})_{12}$ with a promoter of $\mathrm{LiCl}$. It can catalyze the reverse water gas shift reaction, $\mathrm{CO}_{2}+\mathrm{H}_{2} \rightarrow$ $\mathrm{CO}+\mathrm{H}_{2} \mathrm{O}$, and $\mathrm{CO}$ formed will be used for hydroformylation. The presence of $\mathrm{LiCl}$ is crucial in suppressing undesired direct hydrogenation of substrates, according to the works of Tominaga and Sasaki [12] and Jääskeläinen and Haukka [13]. These authors also examined the influence of a few reaction variables but not that of $\mathrm{CO}_{2}$ and $\mathrm{H}_{2}$ pressures in detail.

On the course of their study on chemical reactions in and under pressurized $\mathrm{CO}_{2}$, the present authors indicate an interesting chemical effect of dense $\mathrm{CO}_{2}$ molecules, which interact strongly with a substrate molecule and affect its reactivity. Such interaction and effect occur with an $\alpha, \beta$-unsaturated aldehyde of cinnamaldehyde and this is one of important factors for promoting the selective hydrogenation of its carbonyl group to the corresponding unsaturated alcohol [14-17]. It is thus noteworthy that $\mathrm{CO}_{2}$ may act as not only a reaction medium but also a reaction promoter. Those previous results obtained by Tominaga and Sasaki, Jääskeläinen and Haukka, and our group have motivated us to study the influence of $\mathrm{CO}_{2}$ and $\mathrm{H}_{2}$ pressures in hydrofomylation with $\mathrm{CO}_{2}$ and $\mathrm{H}_{2}$ using those previous authors' best catalyst system.

\section{Results and Discussion}

The hydroformylation of cyclohexene with $\mathrm{CO}_{2} / \mathrm{H}_{2}$ in NMP solvent was conducted under different conditions and the features of this hydroformylation reaction were examined and discussed.

\subsection{Hydroformylation of cyclohexene at different pressures}

The additive effect of $\mathrm{LiCl}$ was already reported in the literature [11-13] but it was briefly examined in this work as well. Table 1 gives the results obtained with different amounts of $\mathrm{LiCl}$ used. When $\mathrm{LiCl}$ was absent or its amount was smaller compared to that of $\mathrm{Ru}_{3}(\mathrm{CO})_{12}$, hydrogenation of cyclohexene to chclohexane and formation of methane and other hydrocarbons mainly occurred but hydroformylation scarcely took place. After these reaction runs, the remaining liquid mixture was black, suggesting that $\mathrm{Ru}_{3}(\mathrm{CO})_{12}$ species released $\mathrm{CO}$ moieties and changed to ruthenium metal colloids. At a larger $\mathrm{LiCl} / \mathrm{Ru}_{3}(\mathrm{CO})_{12}$ ratio of $4 / 3$, however, hydroformylation was observed to proceed,

giving cyclohexanecarboxaldehyde 2 and cyclohexanemethanol 3 along with cyclohexane 4 (Scheme 1), but undesired hydrocarbons were not formed. The reaction mixture was reddish brown in color, indicating that the catalyst still remained in the form of $\mathrm{Ru}_{3}(\mathrm{CO})_{12}$ after the reaction. The following experiments were made to examine the influence of $\mathrm{CO}_{2}$ and $\mathrm{H}_{2}$ pressures at this $\mathrm{LiCl} / \mathrm{Ru}_{3}(\mathrm{CO})_{12}$ ratio of $4 / 3$.

Figure 1 gives typical changes of total conversion and product yields with reaction time. The reaction was timed just after the reaction temperature reached $423 \mathrm{~K}$ and so the reactions occurred to some 
extent at increasing temperatures (the conversion and the yields are not zero at a reaction time of zero). Under the conditions used the three main products were observed to form from cyclohexene $\mathbf{1}$, including cyclohexanecarboxaldehyde $\mathbf{2}$, cyclohexylmethanol $\mathbf{3}$, and cyclohexane 4 (Scheme 1). The conversion of 1 was almost completed in $5 \mathrm{~h}$ and the yield of the hydroformylation product $\mathbf{2}$ increased with time, had a maximum at about $2 \mathrm{~h}$, and then decreased gradually. After about $2 \mathrm{~h}$ the yield of its hydrogenated product $\mathbf{3}$ went over the yield of $\mathbf{2}$ and further increased with time. Thus $\mathbf{3}$ was consecutively formed through the hydrogenation of $\mathbf{2}$. The yield of $\mathbf{4}$, hydrogenation product of $\mathbf{1}$, increased slightly within $3 \mathrm{~h}$ and then did not change so much after the disappearance of the substrate 1. It is indicated that the two paths from 1 to $\mathbf{2}$ (hydroformylation) and from $\mathbf{1}$ to $\mathbf{4}$ (hydrogenation) are parallel reactions. Very minor products such as cyclohexylmethyl cyclohexanecarboxylate, methylenecyclohexane, 1-methyl-1-cyclohexene, and 3-methyl-1-cyclohexene were detected.

Table 1. Influence of the amount of $\mathrm{LiCl}$ additive used on the reactions of cyclohexene with $\mathrm{CO}_{2}$ and $\mathrm{H}_{2}$ using $\mathrm{Ru}_{3}(\mathrm{CO})_{12}$ catalyst.

\begin{tabular}{|c|c|c|c|c|c|c|}
\hline \multirow[b]{2}{*}{ Entry } & \multirow[b]{2}{*}{$\mathrm{LiCl} / \mathrm{Ru}_{3}(\mathrm{CO})_{12}$} & \multicolumn{4}{|c|}{ Product yield (\%) } & \multirow{2}{*}{$\begin{array}{c}\text { Total } \\
\mathrm{CO}^{\mathrm{a}} \\
(\mathrm{mmol})\end{array}$} \\
\hline & & $\begin{array}{l}\text { Cyclohexane- } \\
\text { carboxaldehyde }\end{array}$ & $\begin{array}{c}\text { Cyclohexane- } \\
\text { methanol }\end{array}$ & Cyclohexane & $\begin{array}{l}\text { Hydro- } \\
\text { carbons }\end{array}$ & \\
\hline 1 & $0 / 3$ & 0 & 4 & 60 & 35 & 0.4 \\
\hline 2 & $2 / 3$ & 0 & 1 & 79 & 20 & 0.1 \\
\hline 3 & $4 / 3$ & 23 & 37 & 14 & 0 & 10.7 \\
\hline
\end{tabular}

${ }^{\mathrm{a}}$ Total $\mathrm{CO}=$ cyclohexanecarboxaldehyde + cyclohexanemethanol $+\mathrm{CO}$ (see Scheme 1$)$

Reaction conditions: catalyst $\mathrm{Ru}_{3}(\mathrm{CO})_{12} 0.3 \mathrm{mmol}$, substrate cyclohexene $1 \mathrm{~cm}^{3}(9.87 \mathrm{mmol})$, solvent NMP $8 \mathrm{~cm}^{3}$, pressure $\mathrm{CO}_{2} 3 \mathrm{MPa}, \mathrm{H}_{2} 3 \mathrm{MPa}$, temperature $423 \mathrm{~K}$, time $3 \mathrm{~h}$.

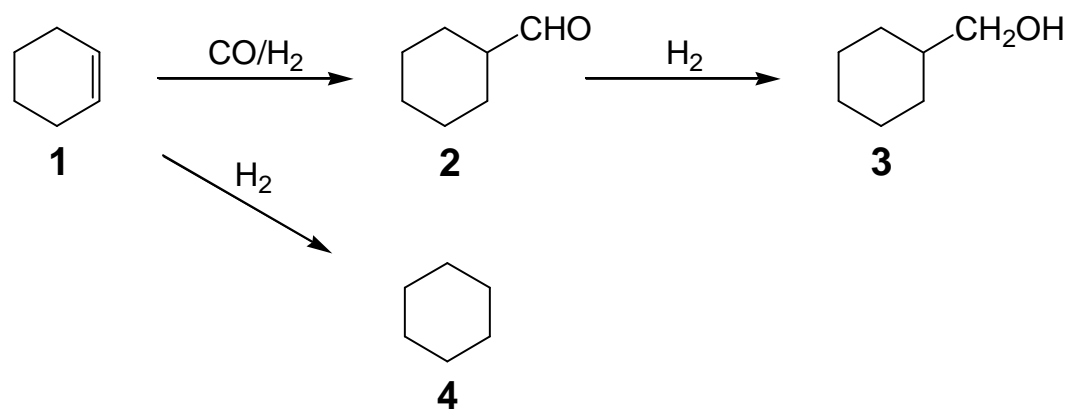

Scheme 1. Transformation of cyclohexene 1 to (path 1) cyclohexanecarboxaldehyde 2 via hydroformylation and then to cyclohexanemethanol $\mathbf{3}$ via hydrogenation and to (path 2) cyclohexane 4 via direct hydrogenation. 


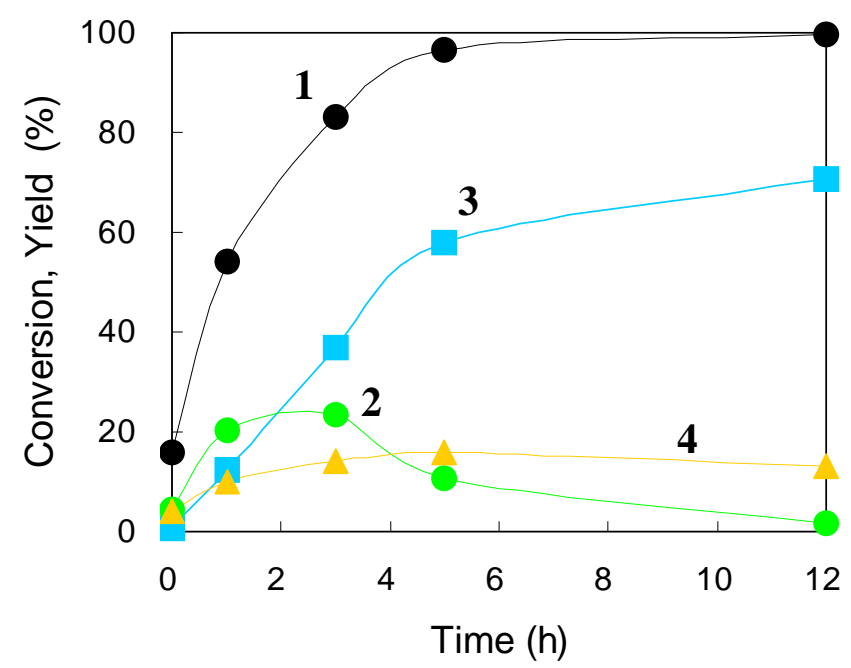

Figure 1. Typical time course of reactions of cyclohexene with $\mathrm{CO}_{2}$ and $\mathrm{H}_{2}$ under conditions: catalyst $\mathrm{Ru}_{3}(\mathrm{CO})_{12} 0.3 \mathrm{mmol}$, substrate cyclohexene $1 \mathrm{~cm}^{3}(9.87 \mathrm{mmol})$, solvent NMP $8 \mathrm{~cm}^{3}$, pressure $\mathrm{CO}_{2} 3 \mathrm{MPa}, \mathrm{H}_{2} 3 \mathrm{MPa}$, temperature $423 \mathrm{~K}$.

The present hydroformylation with $\mathrm{CO}_{2}$ and $\mathrm{H}_{2}$ is a two step process with the reverse water gas shift reaction (RWGSR) followed by the hydroformylation with $\mathrm{CO}$ formed. Table 2 shows the amounts of 2, 3 and $\mathrm{CO}$ gas detected during the reaction run of Figure 1. The amount of $\mathrm{CO}$ gas is comparable to those of $\mathbf{2}$ and $\mathbf{3}$, so the RWGSR is assumed to go faster compared with the following hydroformylation with $\mathrm{CO}$ formed and the latter determines the overall rate of the hydroformylation of 1 with $\mathrm{CO}_{2}$ and $\mathrm{H}_{2}$ to 2 .

Table 2. Amounts of 2, 3, and $\mathrm{CO}$ formed during hydroformylation of cyclohexene with $\mathrm{CO}_{2}$ and $\mathrm{H}_{2}$ using $\mathrm{Ru}_{3}(\mathrm{CO})_{12}$ catalyst ${ }^{\mathrm{a}}$.

\begin{tabular}{ccccc}
\hline \multirow{2}{*}{$\begin{array}{c}\text { Time } \\
\text { (h) }\end{array}$} & $\mathbf{2}$ & $\mathbf{3}$ & $\mathrm{CO}$ & $\begin{array}{c}\mathrm{CO} /(\mathbf{2}+\mathbf{3}+\mathrm{CO}) \\
(\%)\end{array}$ \\
\cline { 2 - 4 } 1 & 2.0 & 1.2 & 2.2 & 41 \\
3 & 2.3 & 3.6 & 4.7 & 44 \\
5 & 1.0 & 5.7 & 8.2 & 55 \\
12 & 0.18 & 7.0 & 8.0 & 53 \\
\hline
\end{tabular}

${ }^{a}$ See Figure 1 for reaction conditions used.

Next the influence of $\mathrm{CO}_{2}$ and $\mathrm{H}_{2}$ pressures has been examined. Figure 2 gives the results obtained at different total pressures while keeping the ratio of $\mathrm{CO}_{2}: \mathrm{H}_{2}$ to $1: 1$. It is indicated that the increasing total pressure promotes the hydroformylation and increases the yields of $\mathbf{2}$ and $\mathbf{3}$ but suppresses the direct hydrogenation of $\mathbf{1}$, decreasing the yield of 4 . A higher pressure of $8 \mathrm{MPa}$ gives a further increased yield of the aldehyde $\mathbf{2}$ while it does not change the yield of its hydrogenated product $\mathbf{3}$ so much. Higher total pressure is beneficial for higher rate of hydrofomylation and higher selectivity to the hydroformylation product (aldehyde) compared to its further hydrogenated product (alcohol). 


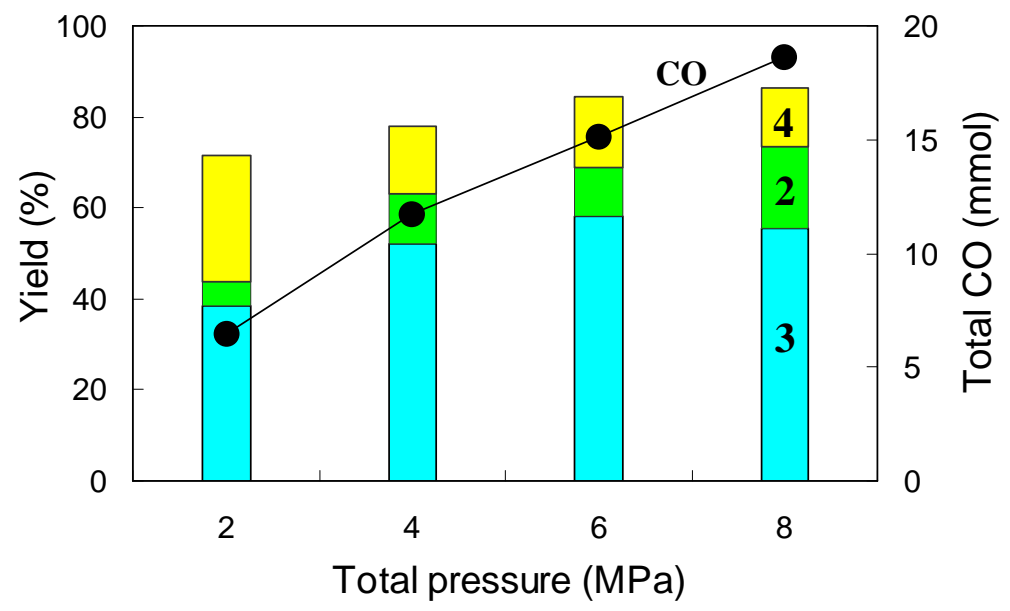

Figure 2. Influence of total pressure of $\mathrm{CO}_{2}$ and $\mathrm{H}_{2}$ (1:1) on the reactions under conditions: catalyst $\mathrm{Ru}_{3}(\mathrm{CO})_{12} 0.3 \mathrm{mmol}$, additive $\mathrm{LiCl} 0.4 \mathrm{mmol}$, substrate cyclohexene $1 \mathrm{~cm}^{3}(9.87 \mathrm{mmol})$, solvent NMP $8 \mathrm{~cm}^{3}$, temperature $423 \mathrm{~K}$, time 3 h. 2 : cyclohexanecarboxaldehyde, 3: cyclohexanemethanol, 4: cyclohexane.

Figure 3 shows the effects of $\mathrm{CO}_{2}$ and $\mathrm{H}_{2}$ pressures at certain $\mathrm{H}_{2}$ and $\mathrm{CO}_{2}$ pressures. The effects of $\mathrm{CO}_{2}$ pressure are similar to those of the total $\mathrm{CO}_{2}+\mathrm{H}_{2}$ pressure as above-mentioned. Figure 3(b) shows that increasing $\mathrm{H}_{2}$ pressure enhances the rates of hydrofomylation and hydrogenation reactions. The yield of $\mathbf{3}$ increases with $\mathrm{H}_{2}$ pressure, while the yield of $\mathbf{2}$ decreases. The yield of $\mathbf{4}$ increases on going from $1 \mathrm{MPa}$ to $2 \mathrm{MPa}$ but does not change at higher $\mathrm{H}_{2}$ pressures. Higher $\mathrm{H}_{2}$ pressure is suitable for higher selectivity for the hydrofomylation and the subsequent hydrogenation than the undesired direct hydrogenation to 4 .
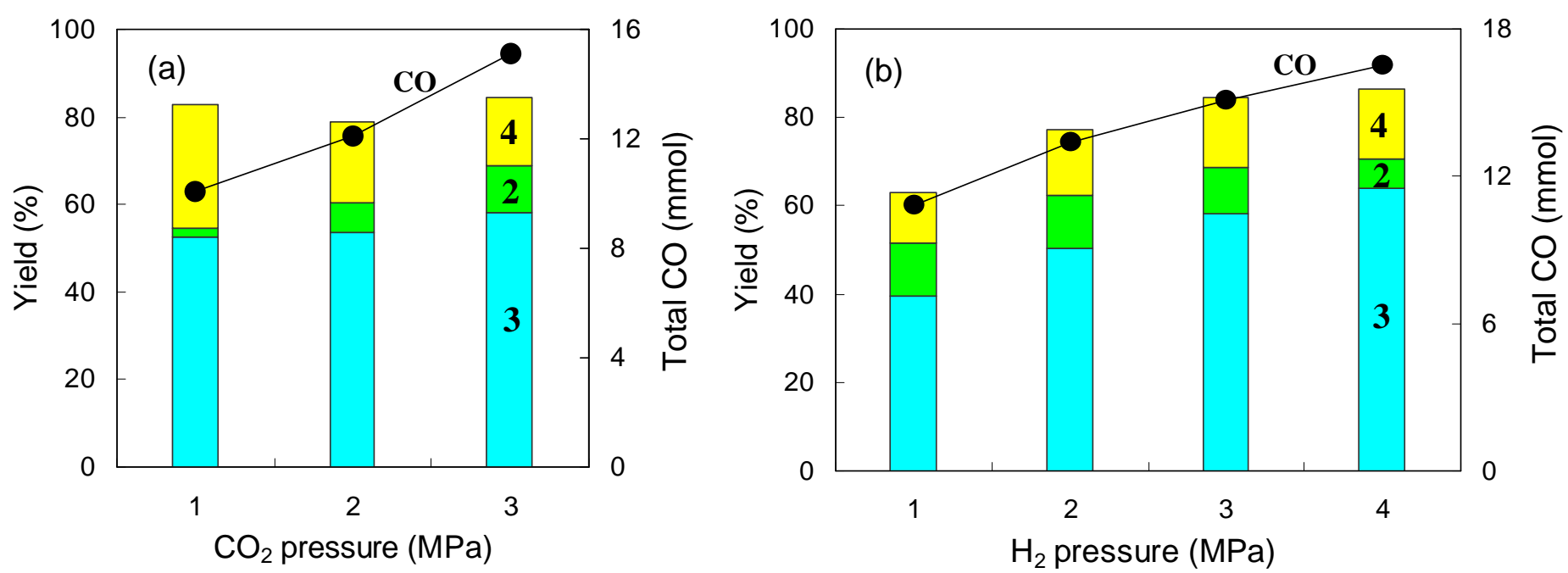

Figure 3. Influence of (a) $\mathrm{CO}_{2}$ pressure at $\mathrm{H}_{2} 3 \mathrm{MPa}$ and (b) $\mathrm{H}_{2}$ pressure at $\mathrm{CO}_{2} 3 \mathrm{MPa}$ under conditions: catalyst $\mathrm{Ru}_{3}(\mathrm{CO})_{12} 0.3 \mathrm{mmol}$, additive $\mathrm{LiCl} 0.4 \mathrm{mmol}$, substrate cyclohexene $1 \mathrm{~cm}^{3}(9.87$ mmol), solvent NMP $8 \mathrm{~cm}^{3}$, temperature $423 \mathrm{~K}$, time 3 h. 2: cyclohexanecarboxaldehyde, 3: cyclohexanemethanol, 4: cyclohexane. 


\subsection{Phase behavior and high pressure FTIR}

Under the reaction conditions used, the reaction mixture is a biphasic system of gas and liquid phases. The phase behavior was confirmed by visual observations at $403 \mathrm{~K}$ (Figure 4), which is a little lower than the reaction temperature $(423 \mathrm{~K})$ due to limitation of the observation system used. The presence of $\mathrm{CO}_{2}$ seems to cause the expansion of the liquid phase but marginally. The hydrofomylation and hydrogenation reactions occur in the liquid phase (NMP solvent).

Previously the present authors show from in situ high pressure FTIR measurements that dense $\mathrm{CO}_{2}$ molecules may strongly interact with organic molecules and modify the reactivity of some of their functional groups [14-17]. There are indeed strong interactions between dense $\mathrm{CO}_{2}$ molecules and an $\alpha, \beta$-unsaturated aldehyde, cinnamaldehyde, in particular with its carbonyl group. This is of significance in promoting the selective hydrogenation to the corresponding unsaturated alcohol,
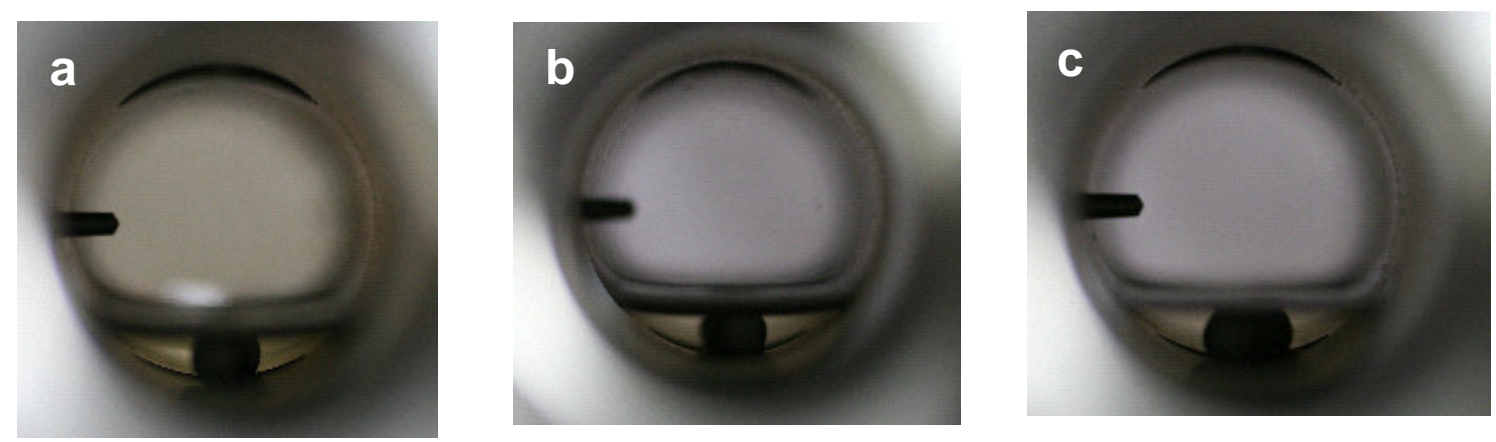

Figure 4. Visual observations of liquid (NMP) - gas biphasic mixtures at $403 \mathrm{~K}$. These are NMP under (a) $4 \mathrm{MPa} \mathrm{H}$, (b) $4 \mathrm{MPa} \mathrm{H}_{2}+4 \mathrm{MPa} \mathrm{CO} \mathrm{MPa}_{2}$, (c) $4 \mathrm{MPa} \mathrm{H}_{2}+16 \mathrm{MPa} \mathrm{CO}_{2}$.

A dark body in the liquid phase is a Teflon stirrer.

cinnamyl alcohol. To examine such a chemical effect of $\mathrm{CO}_{2}$ for the present cases, similar FTIR measurements were also made for the substrate $\mathbf{1}$ and the hydrofomylation product $\mathbf{2}$, which were dissolved in the dense $\mathrm{CO}_{2}$ medium at different pressures. Figure 5 presents FTIR spectra of $\mathbf{1}$ and $\mathbf{2}$ in a mixture of $4 \mathrm{MPa} \mathrm{H}_{2}$ and $\mathrm{CO}_{2}$ at different pressures and at $387 \mathrm{~K}$. Figure 5(a) shows an IR band at around $3030 \mathrm{~cm}^{-1}$ and a very weak band at around $1660 \mathrm{~cm}^{-1}$, which are assigned to the absorption of $=\mathrm{CH}-$ and $-\mathrm{C}=\mathrm{C}-$, respectively. The both bands decrease in the strength with $\mathrm{CO}_{2}$ pressure, due to a simple dilution. Their peak positions little change with the pressure. For $\mathbf{2}$, on the other hand, Figure 5 (b) indicates a single peak at $1743 \mathrm{~cm}^{-1}$ assignable to the absorption of $\mathrm{C}=\mathrm{O}$ at a $\mathrm{CO}_{2}$ pressure of 4 $\mathrm{MPa}$ and a new shoulder peak appears at $8 \mathrm{MPa}$; it marginally increases with the pressure but the peak position remains almost unchanged. The two IR bands assignable to $-\mathrm{CH}_{2}$ - in the region of $2980-2840$ $\mathrm{cm}^{-1}$ do not change their peak positions with $\mathrm{CO}_{2}$ pressure. Thus we believe that dense $\mathrm{CO}_{2}$ molecules indicate no effects on the reactivity of $\mathbf{1}$ and $\mathbf{2}$ to hydrogenation and hydroformylation, respectively, under the present $\mathrm{CO}_{2}$ pressure conditions.

\subsection{Pressure effects}

The structure of $\mathrm{Ru}$ complexes prepared at different $\mathrm{CO}_{2}$ and $\mathrm{H}_{2}$ pressures was examined by FTIR measurements. Figure 6 shows that the complexes (a) - (c) exhibit three strong and two weak IR bands 
in the CO region at 2038, 2018, 1999, 1976, and $1949 \mathrm{~cm}^{-1}$, which are very similar independent of the pressures of $\mathrm{CO}_{2}$ and $\mathrm{H}_{2}$ used for the preparation of them. Previously Tominaga and Sasaki observed similar IR bands [11] and pointed out that these IR bands indicated the presence of two different $\mathrm{Ru}$ complexes, $\left[\mathrm{H}_{3} \mathrm{Ru}_{4}(\mathrm{CO})_{12}\right]^{-1}$ and $\left[\mathrm{HRu}_{3}(\mathrm{CO})_{11}\right]^{-1}$, which may be active for the hydrogenation of $\mathrm{CO}_{2}$ to $\mathrm{CO}$ and the hydrofomylation of alkene with $\mathrm{CO}$, respectively. Those two $\mathrm{Ru}$ complexes should also be formed in our cases and their structure and relative quantities do not change with the $\mathrm{CO}_{2}$ and $\mathrm{H}_{2}$ pressures under the present conditions. Thus, other factors should be considered to explain the pressure effects observed.

(a) 1 (cyclohexene)
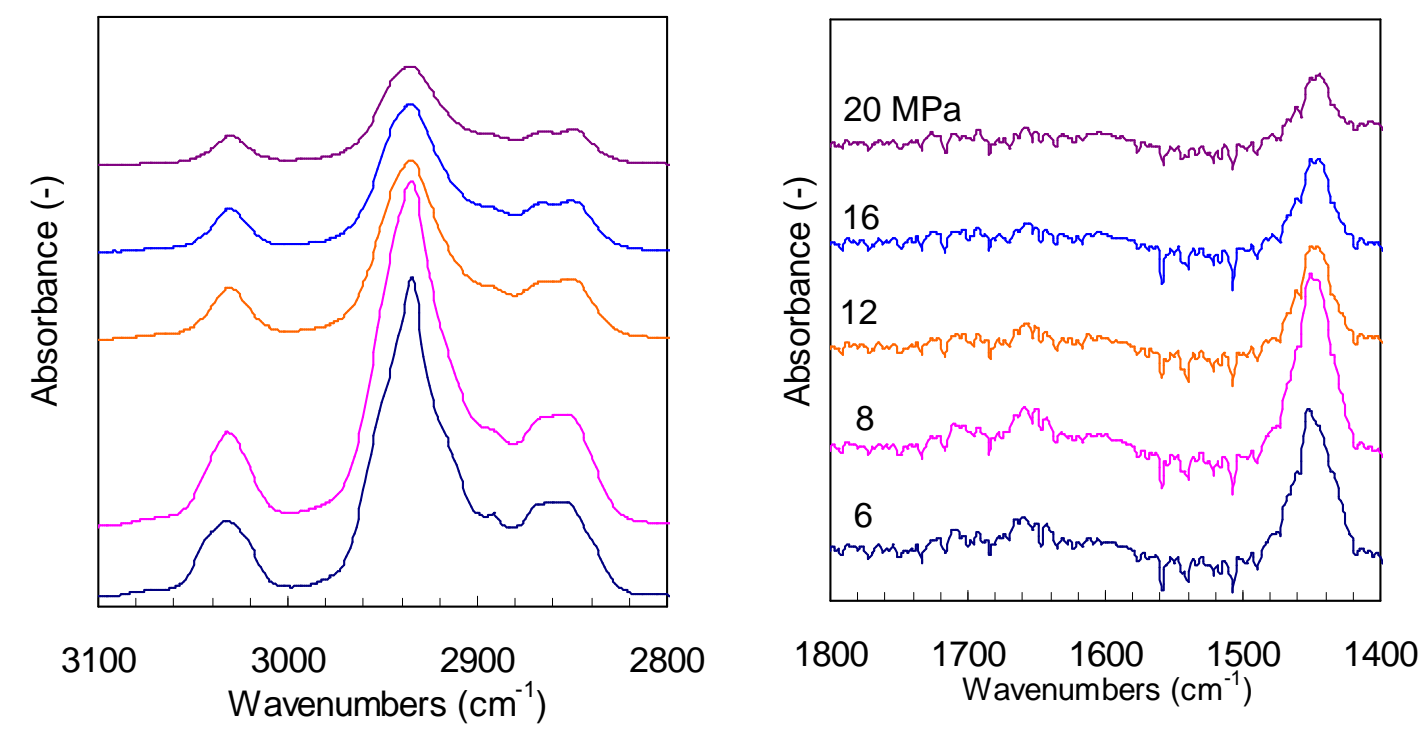

(b) 2 (cyclohexanecarboxaldehyde)
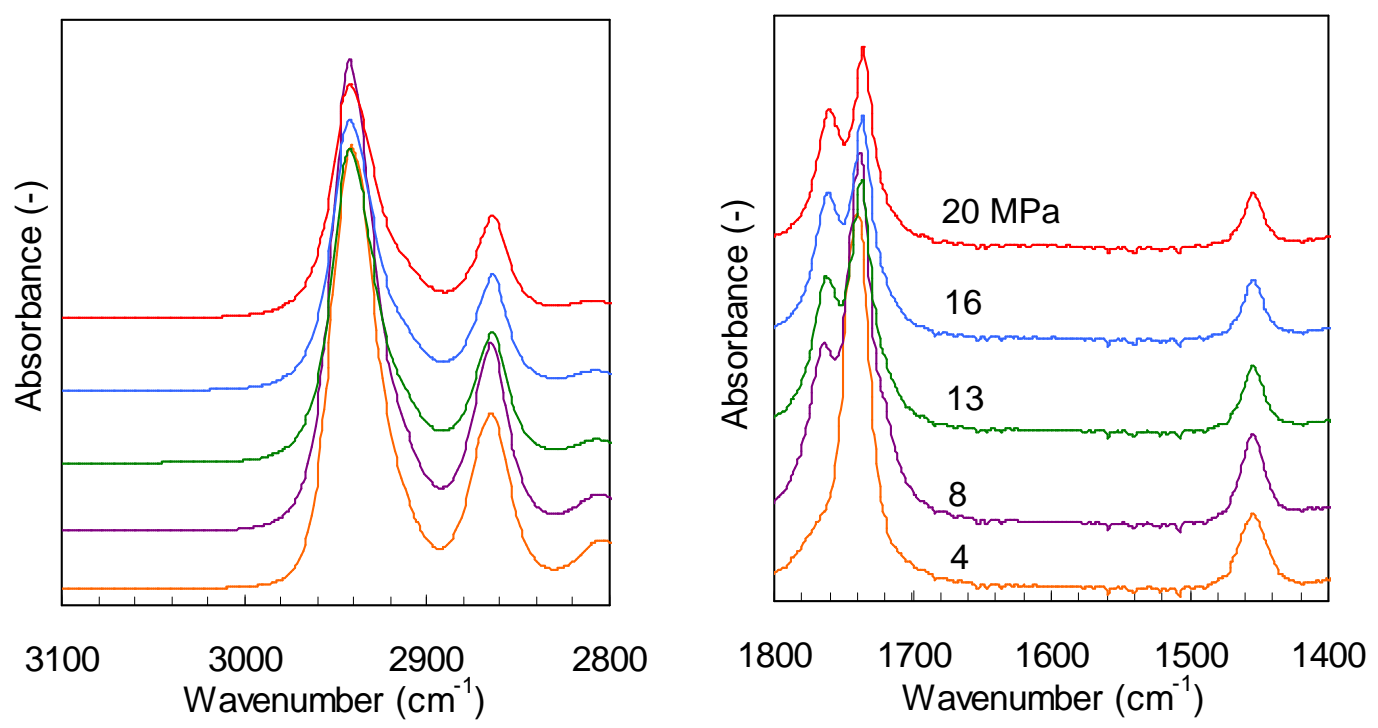

Figure 5. High pressure FTIR spectra of $\mathbf{1}$ and 2 in $4 \mathrm{MPa} \mathrm{H}_{2}$ and dense $\mathrm{CO}_{2}$ at different pressures given and at $387 \mathrm{~K}$. 


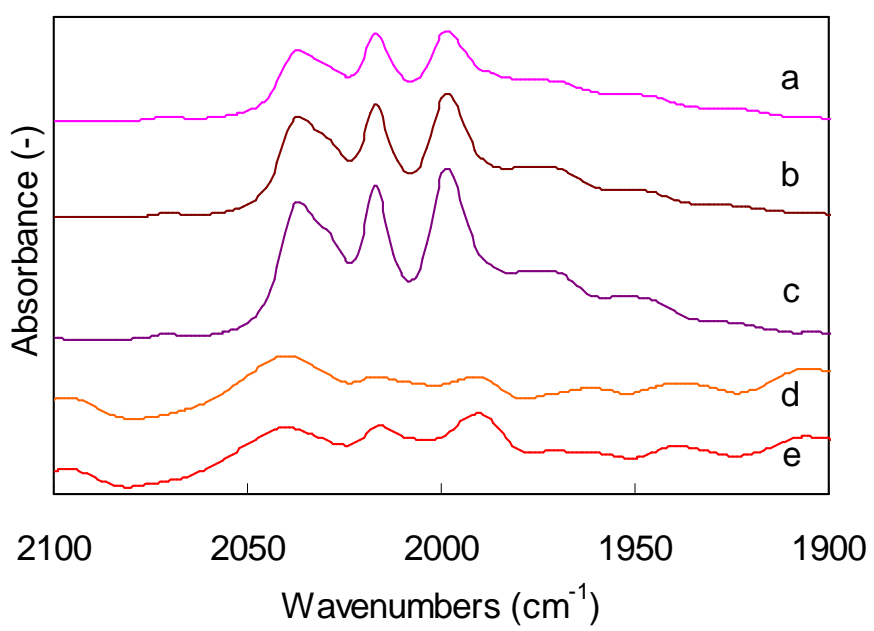

Figure 6. FTIR spectra of catalytically active species prepared in NMP at different $\mathrm{CO}_{2}$ and $\mathrm{H}_{2}$ pressures. $\mathrm{Ru}_{3}(\mathrm{CO})_{12}+\mathrm{LiCl}$ in NMP at (a) $\mathrm{CO}_{2} 3 \mathrm{MPa}, \mathrm{H}_{2} 3 \mathrm{MPa}$; (b) $\mathrm{CO}_{2} 1 \mathrm{MPa}, \mathrm{H}_{2} 3 \mathrm{MPa}$; (c) $\mathrm{CO}_{2} 1 \mathrm{MPa}, \mathrm{H}_{2} 1 \mathrm{MPa}$. (d) $\mathrm{Ru}_{3}(\mathrm{CO})_{12}+\mathrm{LiCl}$ in NMP. (e) $\mathrm{Ru}_{3}(\mathrm{CO})_{12}$ in NMP.

The reactions occur in the liquid phase (NMP) under the conditions used, as confirmed by visual observations (Figure 4). When $\mathrm{CO}_{2}$ and $\mathrm{H}_{2}$ pressures are raised, larger quantities of these gaseous reactants are dissolved in the liquid phase and this promotes the hydroformylation and the following hydrogenation. Thus, the yields of $\mathbf{2}$ and $\mathbf{3}$ tend to increase with the $\mathrm{CO}_{2}$ and $\mathrm{H}_{2}$ pressures (Figures 1$3)$. It is interesting to note that the yield of $\mathbf{4}$ does not increase with $\mathrm{H}_{2}$ pressure and the coexistence of $\mathrm{CO}_{2}$ may be important for this. When $\mathrm{H}_{2}$ pressure is raised at a certain $\mathrm{CO}_{2}$ pressure, the dissolution of $\mathrm{CO}_{2}$ into the liquid phase may also be facilitated. The dissolved $\mathrm{CO}_{2}$ species should suppress the direct hydrogenation of $\mathbf{1}$ to 4 . This may be due to a simple dilution effect that the reactants of $\mathbf{1}$ and $\mathrm{H}_{2}$ in the liquid phase are diluted by the dissolved $\mathrm{CO}_{2}$ molecules. The FTIR results do not indicate that the reactivity of $\mathbf{1}$ is modified through interactions with the $\mathrm{CO}_{2}$ molecules. Additional reaction runs were attempted with the same catalyst system but at lower reaction temperatures ( $393 \mathrm{~K}-323 \mathrm{~K})$ to examine the influence of $\mathrm{CO}_{2}$ pressures on the hydrogenation of $\mathbf{1}$. In those runs, unfortunately, hydroformylation also took place or the overall conversion was small, and these attempts were not successful.

The dissolution of $\mathrm{CO}_{2}$ into the solvent phase would decrease the concentration of $\mathbf{1}$ (and 2) and $\mathrm{H}_{2}$ and this might reduce the rate of hydrogenation of both $\mathbf{1}$ and $\mathbf{2}$. However, the present results show that the conversion of $\mathbf{2}$ to $\mathbf{3}$ is not suppressed. For $\mathbf{2}$ as well, the dense $\mathrm{CO}_{2}$ molecules little affect the reactivity of $\mathbf{2}$ (suggested from FTIR results). The simple hydrogenation of $\mathbf{2}$ was tested with the same catalyst system at a $\mathrm{H}_{2}$ pressure of $3 \mathrm{MPa}$ (in the absence of $\mathrm{CO}_{2}$ ); the conversion was found to be more than $90 \%$ and $60 \%$ at $423 \mathrm{~K}$ (used for hydrofomylation runs) and $393 \mathrm{~K}$, respectively (the conversion was observed to decrease in the presence of $\mathrm{CO}_{2}$ for this hydrogenation of 2 , due to the dilution effect). The hydrogenation of $\mathbf{2}$ to $\mathbf{3}$ is assumed to be faster than the hydrofomylation of $\mathbf{1}$ to $\mathbf{2}$. Under the hydroformylation conditions used, the hydroformylation of $\mathbf{1}$ is promoted with $\mathrm{CO}_{2}$ pressure; this is positive for promoting the subsequent hydrogenation of $\mathbf{2}$, which is against the negative dilution effect. As a result of the balance of these positive and negative effects the hydrogenation of $\mathbf{2}$ to $\mathbf{3}$ should not be suppressed with $\mathrm{CO}_{2}$ pressure, in contrast to that of $\mathbf{1}$ to $\mathbf{4}$ (the simple dilution effect only). 
The effect of $\mathrm{CO}_{2}$ and $\mathrm{H}_{2}$ pressures on the hydroformylation and hydrogenation reactions also includes that of $\mathrm{CO}$ and $\mathrm{H}_{2} \mathrm{O}$ formed via the reverse water gas shift reaction (RWGSR). As mentioned in 2.1., the RWGSR is assumed to go faster compared with the following hydroformylation with $\mathrm{CO}$ formed in the former reaction and the latter should determine the overall rate of hydroformylation of $\mathbf{1}$ with $\mathrm{CO}_{2}$ and $\mathrm{H}_{2}$ under the conditions used. The further detailed discussion on the pressure effects at molecular level should consider the roles of those intermediate and byproduct gases. The volume of NMP liquid phase little changes on the pressurization with $\mathrm{CO}_{2}$ and $\mathrm{H}_{2}$ (Figure 4), and so the species of $\mathbf{1}$ and $\mathbf{2}$ are likely to exist mainly in the liquid phase. This should be confirmed by measurements of the solubility of these species in either NMP liquid phase or dense $\mathrm{CO}_{2}$ gas phase.

In the present work a homogeneous catalyst of $\mathrm{Ru}_{3}(\mathrm{CO})_{12}$ and $\mathrm{LiCl}$ was used, which were soluble and functioned in the solvent phase (NMP in the present case). For practical operation, the separation and recycling of a catalyst is an important aspect for hydroformylation and other reaction processes $[9,18]$. Recently Tominaga and Sasaki attempted to use a biphasic system of an organic solvent and an ionic liquid for hydroformylation using $\mathrm{CO}_{2}$ and $\mathrm{H}_{2}$ [19,20]. They screened several couples of organic solvents and ionic liquids and showed that the hydrofomylation of 1-hexene proceeded and $\mathrm{Ru}$ complex catalysts were recyclable for some couples. Under the conditions, however, alcohol was selectively formed but no aldehyde was obtained. The heterogenization of catalytic reaction systems and the control of product selectivity are also interesting and challenging tasks for hydroformylation with $\mathrm{CO}_{2}$ and $\mathrm{H}_{2}$.

\section{Experimental Section}

Commercially available reagents were used without further purification: catalyst $\mathrm{Ru}_{3}(\mathrm{CO})_{12}$ purchased from Aldrich and $\mathrm{LiCl}, \mathrm{NMP}$ (solvent), and cyclohexene from Wako. $\mathrm{Ru}_{3}(\mathrm{CO})_{12} 0.3 \mathrm{mmol}$, LiCl $0.4 \mathrm{mmol}$, cyclohexene $1 \mathrm{~cm}^{3}(9.87 \mathrm{mmol})$, and NMP $8 \mathrm{~cm}^{3}$ were mixed in a $100 \mathrm{~cm}^{3}$ stainless reactor with Teflon-coated inner wall. Then $\mathrm{CO}_{2}$ and $\mathrm{H}_{2}$ (reagent grade) were introduced into the reactor up to the desired pressures at room temperature and the reactor was sealed and heated to a reaction temperature of $423 \mathrm{~K}$ while mixing the reaction mixture. In this work, these initial $\mathrm{CO}_{2}$ and $\mathrm{H}_{2}$ pressures are given in reaction conditions. After reaction runs, the mixing was stopped and the reactor was cooled down to room temperature. The reaction products, liquid and gaseous species, were analyzed with gas chromatographs, GL Science GC390B, Hitachi G-3000, Shimadzu GC-14B and a gas chromatograph - mass spectrometer Shimadzu GCMS-QP5050A. The conversion of cyclohexene was determined by (initial amount $(9.87 \mathrm{mmol})$ - residual amount measured) / initial amount. The total quantity of $\mathrm{CO}$ formed was estimated by summing the amounts of hydrofomylation product (cyclohexanecarboxaldehyde), its further hydrogenation product (cyclohexanemethanol), and $\mathrm{CO}$ remaining in the gas phase.

The phase behavior of reaction mixture was examined by the naked eye using another reactor attached with transparent quartz windows. The liquid phase used was NMP alone since the concentration of cyclohexene used in the reaction runs was small. In addition, in situ high pressure FTIR was used to study interactions of cyclohexene and some products with dense $\mathrm{CO}_{2}$ molecules. The experimental setups and procedures for these visual observation and FTIR measurement were described in previous works $[15,16]$. The structure of catalytically active species was also examined by FTIR. The $\mathrm{Ru}$ complexes were prepared at different $\mathrm{CO}_{2}$ and $\mathrm{H}_{2}$ pressures in the abovementioned 
manners, kept for $1 \mathrm{~h}$ under the reaction conditions (in the absence of cyclohexene), and were then subjected to FTIR measurements under ambient conditions. For the FTIR measurements a small quantity of NMP liquid containing the active species was held between two KBr plates but it was not precisely measured and so the absolute strength of IR bands observed was not considered in this work.

\section{Acknowledgements}

This work was supported by Grant-in-Aid for Scientific Research, Japan Society for the Promotion of Science (B-18360378).

\section{References and Notes}

1. Jessop, P.G.; Leitner, W., Eds. Chemical Synthesis Using Supercritical Fluids; Wiley-VCH: Weinheim, 1999.

2. Leitner, W. Supercritical Carbon Dioxide as a Green Reaction Medium for Catalysis. Acc. Chem. Res. 2002, 35, 746-756.

3. Beckman, E.J. Supercritical and Near-critical $\mathrm{CO}_{2}$ in Green Chemical Synthesis and Processing. $J$. Supercrit. Fluids 2004, 28, 121-191.

4. Clarke, D.; Ali, M.A.; Cliford, A.A.; Parratt, A.; Rose, P.; Schwinn, D.; Bannwarth, W.; Rayner, C.M. Reactions in Unusual Media. Curr. Top. Med. Chem. 2004, 4, 729-771.

5. Fujita, S.; Bhanage, B.M.; Arai, M. Chemical Fixation of Carbon Dioxide: Green Processes to Valuable Chemicals. In Progress in Catalysis Research; Bevy, L. P., Ed.; Nova Science: New York, 2005: pp. 57-79.

6. Sun, J.; Fujita, S.; Arai, M. Development in the Green Synthesis of Cyclic Carbonate from Carbon Dioxide Using Ionic Liquids. J. Organomet. Chem. 2005, 690, 3490-3497.

7. Fujita, S.; Arai, M. Chemical Fixation of Carbon Dioxide: Synthesis of Cyclic Carbonate, Dimethyl Carbonate, Cyclic Urea and Cyclic Urethane. J. Jpn. Petrol. Inst. 2005, 48, 67-75.

8. Weissermel, K.; Arpe, H.-J. Industrial Organic Chemistry; Wiley-VCH: Weinheim, 1997.

9. Cornils, B.; Herrmann, W.A. Applied Homogeneous Catalysis with Organometallic Compounds; Wiley-VCH:Weinheim, 2000.

10. There are reported a number of works on hydroformylation reactions in $\mathrm{CO}_{2}$ media using various homogeneous and heterogeneous catalysts. See Fujita, S.; Fujisawa, S.; Bhanage, B.M.; Ikushima, Y.; Arai, M. Hydroformylation of 1-Hexene Catalyzed with Rhodium Fluorinated Phosphine Complexes in Supercritical Carbon Dioxide and in Conventional Organic Solvents: Effects of Ligands and Pressures. New J. Chem. 2002, 26, 1479-1484 and references therein.

11. Tominaga, K.; Sasaki, Y. Ruthenium Complex-catalyzed Hydroformylation of Alkenes with Carbon Dioxide. Catal. Commun. 2000, 1, 1-3.

12. Tominaga, K.; Sasaki, Y. Ruthenium-catalyzed One-pot Hydroformylation of Alkenes Using Carbon Dioxide as a Reactant. J. Mol. Catal. A Chem. 2004, 220, 159-165.

13. Jääskeläinen, S.; Haukka, M. The Use of Carbon Dioxide in Ruthenium Carbonyl Catalyzed 1Hexene Hydroformylation Promoted by Alkali Metal and Alkaline Earth Salts. Appl. Catal. A Gen. 2003, 247, 95-100.

14. Zhao, F.; Fujita, S.; Sun, J.; Ikushima, Y.; Arai, M. Carbon Dioxide-expanded Liquid Substrate 
phase: An Effective Medium for Selective Hydrogenation of Cinnamaldehyde to Cinnamyl Alcohol. Chem. Commun. 2004, 2326-2327.

15. Zhao, F.; Fujita, S.; Akihara, S.; Arai, M. Hydrogenation of Benzaldehyde and Cinnamaldehyde in Compressed $\mathrm{CO}_{2}$ Medium with a Pt/C Catalyst: A Study on Molecular Interactions and Pressure Effects. J. Phys. Chem. A 2005, 109, 4419-4424.

16. Fujita, S.; Akihara, S.; Zhao, F.; Liu, R.; Hasegawa, M.; Arai, M. Selective Hydrogenation of Cinnamaldehyde Using Ruthenium-phosphine Complex Catalysts with Multiphase Reaction Systems in and under Pressurized Carbon Dioxide: Significance of Pressurization and Interfaces for the Control of Selectivity. J. Catal. 2005, 236, 101-111.

17. Liu, R.; Zhao, F.; Fujita, S.; Arai, M. Selective Hydrogenation of Citral with Transition Metal Complexes in Supercritical Carbon Dioxide. Appl. Catal. A Gen. 2007, 316, 127-133.

18. Bhanage, B.M.; Arai, M. Catalyst Product Separation Techniques in Heck Reaction, Catal. Rev. Sci. Eng. 2001, 43, 315-344.

19. Tominaga, K.; Sasaki, Y. Biphasic Hydroformylation of 1-Hexene with Carbon Dioxide Catalyzed by Ruthenium Complex in Ionic Liquids. Chem. Lett. 2004, 33, 14-15.

20. Tominaga, K. An Environmentally Friendly Hydroformylation Using Carbon Dioxide as a Reactant Catalyzed by Immobilized Ru-complex in Ionic Liquids. Catal. Today 2006, 115, 70-72.

(C) 2007 by MDPI (http://www.mdpi.org). Reproduction is permitted for noncommercial purposes. 